\title{
OS Cadernos de planeJamento de Matemática e os Vestígios Da Matemática Moderna na déCada de 1980
}

\author{
THE PLANNING NOTEBOOKS OF MATHEMATICS AND THE TRACES OF MODERN \\ MATHEMATICS IN THE 1980S
}

LOS CUADERNOS DE PLANIFICACIÓN DE LA MATEMÁTICA Y LAS HUELLAS DE LA MATEMÁTICA MODERNA EN LOS AÑOS OCHENTA

\section{Luiz Eduardo Brescovit \\ (iD) 9 \\ Mestre em Ensino \\ (UNIC/CUIABÁ) \\ Coordenador do curso de \\ Pedagogia (FAEST) \\ luiz.brescovit@prof.uniserratga.co $\underline{\text { m.br }}$}

\section{Laura Isabel Marques Vasconcelos de Almeida (iD) 9}

Doutora em Educação (PUC-PR)

Docente do Programa de Pós-

Graduação em Ensino (UNIC) e do

Programa de Pós Graduação em

Educação em Ciências e

Matemática

(PPGECEM/REAMEC)

lauraisabelvasc@hotmail.com

\begin{abstract}
Resumo
Este artigo faz parte de uma dissertação de mestrado com viés histórico e tem como objetivo analisar os cadernos de planejamento da disciplina de matemática de uma professora que ministrou aulas na $4^{\mathrm{a}}$ série da escola pública primária no interior do Paraná. A abordagem metodológica centra-se na vertente histórico-cultural e apoia-se nos conceitos de historiadores e autores que discutem os conceitos inerentes a temática da pesquisa. As fontes documentais ancoram-se nos cadernos que registram os planos de aula de matemática, além de documentos oficiais e escolares, manual do professor, fotografias, brochuras e certificados de cursos, que contribuíram para a construção do enredo do ensino de matemática em conformidade com o recorte temporal da pesquisa. Conclui-se que durante a análise dos arquivos escolares, tanto os cadernos, como os documentos oficiais estavam em consonância ao Movimento da Matemática Moderna, considerando o estruturalismo dos conteúdos, bem como, os registros advindos dos cadernos de planejamento.

Palavras-chave: Cadernos Docentes. Matemática Moderna. Ensino.
\end{abstract}

Recebido em: 9 de julho de 2021.

Aprovado em: 2 de outubro de 2021.

Como citar esse artigo (ABNT):

BRESCOVIT, Luiz Eduardo; ALMEIDA, Laura Isabel Marques Vasconcelos de. Os cadernos de planejamento de Matemática e os vestígios da Matemática Moderna na década de 1980. Revista Prática Docente, v. 6, n. 3, e085, 2021. http://doi.org/10.23926/RPD.2021.v6.n3.e085.id1264 


\section{Abstract}

This article is part of a master's thesis with a historical bias and aims to analyze the planning notebooks for the discipline of mathematics of a teacher who taught classes in the 4th grade of public elementary school in the interior of Paraná. The methodological approach is centered on the historical-cultural aspect and is supported by the concepts of historians and authors who discuss the concepts inherent to the research theme. Documentary sources are anchored in notebooks that record mathematics lesson plans, in addition to official and school documents, teacher's manual, photographs, brochures and course certificates, which contributed to the construction of the plot of mathematics teaching in accordance with the time frame of the research. It is concluded that during the analysis of the school files, both the notebooks and the official documents were in line with the Modern Mathematics Movement, considering the structuralism of the contents, as well as the records arising from the planning notebooks.

Keywords: Faculty Notebooks. Modern Mathematics. Teaching.

\section{Resumen}

Este artículo es parte de una tesis de maestría con sesgo histórico y tiene como objetivo analizar los cuadernos de planificación para la disciplina de matemáticas de un maestro que impartió clases en el $4^{\circ}$ grado de la escuela primaria pública en el interior de Paraná. El enfoque metodológico se centra en el aspecto histórico-cultural y se apoya en los conceptos de historiadores y autores que discuten los conceptos inherentes al tema de investigación. Las fuentes documentales están ancladas en cuadernos que registran planes de lecciones de matemáticas, además de documentos oficiales y escolares, manual del profesor, fotografías, folletos y certificados de curso, que contribuyeron a la construcción de la trama de la enseñanza de las matemáticas de acuerdo con el marco temporal de la investigación. Se concluye que durante el análisis de los archivos escolares, tanto los cuadernos como los documentos oficiales estuvieron en línea con el Movimiento Matemático Moderno, considerando el estructuralismo de los contenidos, así como los registros derivados de los cuadernos de planificación.

Palabras clave: Cuadernos de Facultad. Matemática Moderna. Docencia. 


\section{INTRODUÇÃO}

Como historiador, reconhecer o contexto cultural que se insere, as fontes de pesquisa com ênfase nos métodos, princípios teóricos e didáticos das disciplinas escolares viabilizados pelos professores em tempos diferentes dos atuais, demanda não somente autonomia que se estabelece durante a produção científica, como também, cabe a ele o garimpo e uma investigação aprofundada em busca de vestígios que legitimem a construção teórica a qual se debruça.

Este artigo é parte da pesquisa de Mestrado no Programa de Pós-Graduação em Ensino da Universidade de Cuiabá/UNIC e apoia-se na vertente Histórico-Cultural, com objetivo de analisar o ensino de matemática presente nos cadernos de planejamento de uma professora primária na década de 1980, na cidade de Guaraniaçu, no estado do Paraná.

A pesquisa vincula-se também, aos estudos do GHEMAT Brasil - Grupo de Pesquisa de História da Educação Matemática que conta com os diversos pesquisadores nas diferentes regiões do país e no cenário internacional contribuindo com várias temáticas para o campo historiográfico da Educação Matemática.

Ao adentrarmos nesta seara, faz-se necessário revisitar a História da Educação com o intento de reconstituir os ritos de passagem dos programas educacionais que permearam o recorte temporal do nosso estudo. O caminho metodológico permite a literatura especializada de historiadores e autores que discutem os conceitos de cultura (GEERTZ, 1989); apropriação e interpretação (CHARTIER, 1990); disciplinas escolares (CHERVEL, 1990;) cultura escolar (JULIA, 2001); cadernos escolares (MIGNOT, 2010) e História da Educação Matemática (VALENTE 2008).

O intento deste artigo, além de contribuir com a construção científica concebendo a importância da materialidade escolar, permite revisitar um passado recente, com a tarefa de buscar vestígios da cultura escolar de outros tempos, culminando na construção de uma história que fora vivenciada, porém, não foi registrada. Outro aspecto refere-se à produção de trabalho com viés histórico, que ainda apresentam poucas produções, quando comparadas a relevância da temática.

A pesquisa associada ao GHEMAT Brasil - Grupo de Pesquisa de História da Educação Matemática, coordenado pelo Professor Dr. Wagner Rodrigues Valente, conta com pesquisadores nas diversas regiões do país e no cenário internacional que contribuem com várias temáticas do campo historiográfico da educação matemática. 
É certo que a educação passou por modificações no processo de transformações nas legislações e no currículo ao longo dos anos. O GHEMAT Brasil (Grupo de Pesquisa de História da Educação Matemática) mergulhou no desafio de compilar pesquisas com viés histórico de diversas regiões do país, com intuito de constituir produções que abordem os saberes elementares matemáticos das escolas primárias de diferentes épocas. Trata-se de um projeto macro com o desafio de constituir uma base de dados sobre a historiografia da educação matemática, reconhecendo os arquivos escolares como um "diamante bruto" a ser lapidado.

Nesta perspectiva produzir pesquisa na abordagem histórico cultural requer do historiador a tarefa árdua na busca de documentos e elementos que contribuam para a narrativa de fatos que de forma organizada e racional desvele práticas escolares até então desconhecidas. Neste cenário destacamos os cadernos de planejamentos como fonte primária na obtenção de informações daquela época.

Com a premissa de fortalecer estudos sobre os arquivos escolares como fonte de pesquisa, Valente (2008, p.13) avulta que os documentos do passado, "nos revelam o processo histórico e ajuda a entender a organização dos ensinos escolares e o processo que a Matemática escolar foi constituída até chegar às salas de aula". Partindo dessa premissa, elaboramos este artigo, considerando que há várias fontes que precisam ser investigadas e exploradas para tentar explicar como se deu o ensino da Matemática, como afirma o autor.

Para além das determinações postas na legislação educacional todo um conjunto de documentos escolares transforma-se em fonte para a pesquisa da história dos ensinos, das práticas educativas. Livros didáticos, provas e exames realizados pelos alunos, documentos de professores, cadernos escolares, entre muitos outros, constituem elementos fundamentais para a compreensão do trabalho didático-pedagógico realizado noutros tempos (VALENTE, 2008)

A escola é portadora de uma cultura própria e ao longo dos anos tornou-se porta-voz de uma tradição curricular que contempla diferentes disciplinas. Descobrir os cadernos de Planos de aula da escola primária permitiu-nos a assumir a postura de historiador evidenciando a riqueza cultural que trazem os arquivos escolares, pois são fontes moldadas por uma cultura que permeiam as gerações e contam a história do ensino de outros tempos, permitindo uma releitura e possibilidades de inúmeras pesquisas.

Reconhecendo que possivelmente não estejam prescritas as finalidades do ensino nos textos oficiais que fomentam essa pesquisa, em consonância com as análises de Chervel (1990), 
tornou-se relevante buscar outros vestígios que validem as informações extraídas do objeto de estudo.

Este artigo, expõe em seu primeiro tópico, definições sobre Cultura Escolar apresentando a relação entre o objeto de estudo com este conceito. Em seguida, busca localizar historicamente os objetos de estudo, cujo período foi caracterizado pelo Movimento da Matemática Moderna. A seguir, apresenta o percurso metodológico para a realização desta pesquisa, culminando na apresentação dos conteúdos encontrados nesta trajetória, destacando posteriormente, as discussões que acercam o contexto histórico cultural, quanto os conteúdos presentes nestes materiais, e por fim, as considerações que atestam legitimidade a essa pesquisa.

\section{CULTURA ESCOLAR E A MATERIALIDADE ESCOLAR}

O conceito de Cultura é um tema recorrente em pesquisas no campo historiográfico educativo. Tendo como referência os autores Geertz (1989) e Chervel (1990) reconhecemos a importância que a cultura influi no processo de ensino e aprendizagem ao longo dos anos, principalmente, quando relacionados a outras épocas. É sabido que a cultura, tornou-se um porta-voz nas descrições do campo escolar, por tratar-se de um componente completamente presente na vida do ser humano.

Para Geertz (1989, pg.103), "a cultura é regida pelos padrões de significados, codificada em símbolos e transmitida historicamente, mediante os quais as pessoas se comunicam, transmitem e desenvolvem seus conhecimentos e atitudes sobre a vida, que passam de geração em geração podendo ser reproduzidas ou transformadas".

Almeida (2010), nos seus estudos de doutoramento, apoia-se em Geertz (1989), quando define que o termo cultura refere-se ao significado que os sujeitos atribuem no modo de ver e conceber o objeto, depende do olhar de cada pesquisador, onde cada um vê o mesmo objeto, porém, na semiótica da interpretação, apresenta-se diferente do outro, com detalhes e características pessoais distintas.

Outro aspecto a ser levado em consideração quanto as definições das questões culturais detém a ótica de Chervel (1990), consolidando a informação de que a escola não tem apenas por finalidade "instruir as crianças e os adolescentes, mas também lhes dar uma cultura sólida" podendo, portanto, contextualizar o cotidiano escolar dos alunos dando-lhes a concepção de uma cultura que lhe é própria.

Para melhor compreensão sobre história cultural, buscou-se a definição dada por Chartier (2002, p.16-17), que as descreve como pesquisas as quais tem como premissa 
"identificar o modo como em diferentes lugares e momentos uma determinada realidade social é construída, pensada, dada a ler" levando em consideração de que a história é vivida em tempos diferentes dos atuais. Trabalhar na perspectiva histórico-cultural implica buscar essas fontes e falar sobre tudo o que as envolvem, pois é por meio delas que se identificam as características de um povo e a forma de organização das sociedades de épocas diferentes.

A partir dessas considerações, direcionamos o olhar as concepções que envolvem a escola, que tem se tornando alvo frequente de pesquisas em vários países investigando os mais variados tipos de pesquisas. "Da história à sociologia, da política educacional à prática pedagógica, cada uma dessas abordagens tem servido para colocá-la no centro das pesquisas educacionais" (SILVA, 2006, p. 202).

Viñao Frago (2000) ressalta que a cultura escolar não é somente uma consequência de espaços educacionais, e converge aos pensamentos de que a cultura está associada as origens da escola, pois dela emergem contextos que remetem ao cerne daquele determinado lugar, tendo como protagonistas destes estudos, toda a comunidade escolar, os modos de gestão e organização escolar, o sistema educativo as práticas e discussões acerca das disciplinas (SILVA, 2006).

A cultura escolar aponta evidências que a escola é também um local de "inculcação de comportamentos e de habitus", não somente faz alusão a transmissão de conhecimentos acadêmicos, reconhecendo que os fatores sociais possuem ligação direta com o contexto abordado e trabalhado em sala de aula (JULIA, 2001, p. 14).

A cultura gera significados associados ao contexto histórico, político, religioso e social aos quais estavam imbuídos. Os elementos da cultura material representam os valores e desejos de uma sociedade e, neste caso, os cadernos de planejamento configuram-se como um elemento pertencente a esta sociedade que emerge de uma cultura própria, a cultura escolar, representados pela materialidade que resiste aos tempos, aportando a construção histórica das disciplinas escolares de modo geral.

A escola ao longo dos anos tornou-se porta-voz de uma tradição curricular que contempla as diferentes disciplinas. Ao inventariarmos os cadernos de planejamento, fica evidenciado que o primeiro passo neste processo investigativo foi de assumir o ofício de historiador, reconhecendo que os arquivos escolares são fontes que merecem ser exploradas e investigadas, nos remetendo as práticas escolares de outros tempos, permitindo uma releitura e possibilidades de inúmeras pesquisas. 
$\mathrm{Na}$ diversidade de significados que são representados pela escola, destaca-se a materialidade escolar como um elemento essencial, responsável por apontar indícios do ensino, currículo, avanços e os retrocessos, ocorridos nos espaços escolares considerando as transformações ao longo dos tempos. Vidal (2005) contempla como parte desta materialidade, os espaços escolares, as disciplinas, o cotidiano educacional, as tarefas diárias de professores, alunos, arquitetura da escola, espaços de convívio, e todos esses elementos contribuem para reconstruir uma história institucional.

Forquin (1993, p.167), também assevera que "a escola é também um mundo social", que tem suas características próprias, seus ritos, sua linguagem, seu imaginário, seus modos próprios de regulação, seu regime próprio de produção e de gestão de símbolos". Sondando esta afirmativa, percebe-se notoriamente que ela é detentora de sua própria cultura somada a todos os itens que a compõe desde o espaço geográfico, a arquitetura, os materiais escolares utilizados pelos alunos, a lousa, o uniforme entre outros.

Entende-se que os cadernos escolares são frutos desta materialidade escolar, e para tanto, conceituá-los requer do pesquisador a expertise sobre as discussões a respeito da temática. Mignot (2008) esclarece:

Repletos de letras trêmulas, borrões de tintas, traços vermelhos, decalques, exercícios, frases edificantes, bilhetes, elogios e reprimendas - marcas da aprendizagem e do exercício da escrita, velhos cadernos escolares têm permanecido esquecidos em gavetas, caixas e armários (MIGNOT, 2008, p.7)

Tão importante quanto os cadernos escolares dos alunos no processo de ensino e aprendizagem, são os cadernos do professor. São materiais que contém registros pessoais e os conteúdos elaborados de forma sistemática, além de apontamentos que podem indicar a postura profissional e a didática do professor, suas preferências e as mais variadas anotações sobre a metodologia adotada e as sequências didáticas da sua prática pedagógica em sala de aula. A partir deste ponto de vista, os cadernos escolares constituem-se como uma fonte de pesquisa e como um material recheado de detalhes e informações pelo qual objetivou-se investigar e analisar nas entrelinhas para reconstituir a história do ensino de matemática de outros tempos.

Durante as análises, os cadernos de planejamento da professora primária (Figura1) buscam retratar a pedagogia adotada na época, que apontam com clareza os conteúdos trabalhados na disciplina de matemática, ministrada na $4^{\mathrm{a}}$ série do Grupo Escolar Rocha Pombo na década de 1980, apresenta os saberes profissionais, advindos de sua formação escolar e profissional. 
Figura 1 - Cadernos de Planejamentos - 1985/1986

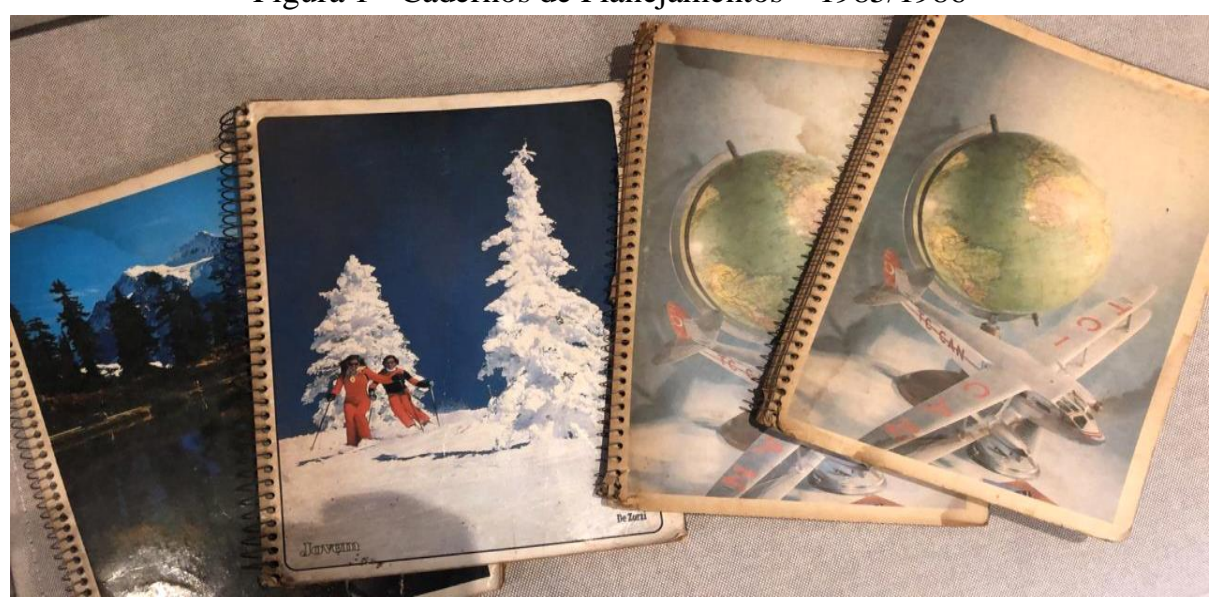

Fonte: Acervo pessoal do autor.

Na década de 1980, o país encontrava-se no período de transição de um governo ditatorial sendo marcado por uma abertura política a qual propunha novos rumos para a educação. Neste contexto o discurso já entoava sobre o Movimento da Matemática Moderna, indicando a presença de vestígios do movimento contrapondo-se ao ensino considerado tradicional, estruturalista, com abordagem tecnicista que predominava no processo de ensino e aprendizagem da época, destacados a seguir.

\section{Vestígios da PRESEnÇA da MATEMÁtica Moderna}

O movimento da Matemática Moderna (MMM) surge em consonância aos acontecimentos políticos que afetaram direta ou indiretamente os processos educacionais por meio da transição de um regime ditatorial ao período democrático (1985).

O ensino da Matemática na tendência tradicional recebeu severas críticas da forma como abordava os conteúdos, somados a descontentamento de professores, bem como os resultados insatisfatórios dos alunos na aprendizagem. A intenção era buscar uma Matemática que se apresentasse mais eficaz e pudesse resolver de forma clara os problemas matemáticos. Reconhecendo esforços entre países europeus, um grupo de americanos perfila também a necessidade de mudança, empenhando-se nesta reforma educacional, concentrando olhares sobre o currículo, alegando que tais mudanças na prática do ensino de Matemática resultariam em melhorias (PINTO, 2007).

Este movimento foi suscitado em âmbito internacional em meados da década de 1950. Teve como premissa uma reorganização nos conteúdos tradicionais da Matemática, conferindo grande importância às questões de conjuntos, aos contextos relacionados a axiomatização e a estruturação algébrica (PINTO, 2007). 
No contexto nacional pode-se considerar que o Estado de São Paulo foi o pioneiro do movimento, iniciando o grupo de pesquisas envolvendo a temática denominada Grupo de Estudos do Ensino da Matemática (GEEM), liderado pelo professor Osvaldo Sangiorgi, o qual mergulhou nas mudanças e divulgação das ideias trazidas pelo MMM. No período, o movimento ganhou grande notoriedade e de acordo com Soares (2005), desde 1960 o grupo, com afinco, buscou difundir tais propostas de modernização do ensino de Matemática por meio de publicações, em renomados jornais do Estado.

No Brasil, os principais matemáticos que contribuíram para a modernização foram Osvaldo Sangiorgi, Jacy Monteiro, Omar Catunda e Benedito Castrucci; na década de 1960 tiveram como pilar influenciador o grupo Bourbaki. Este compreende um Grupo de Matemáticos franceses que usavam o pseudônimo de Nicolas Bourbaki, criado em 1934 que teve um papel importante no Movimento da Matemática Moderna, o grupo defendia uma evolução e revolução interna na Matemática, às quais chamou de estruturas-mãe, composto por matemáticos franceses que na década de 1940, foram contratados pela Faculdade de Filosofia, Ciências e Letras da Universidade de São Paulo (COUSIN, 2011).

Vale ressaltar que naquele momento, a grande premissa do grupo era divulgar e difundir uma modernização da Matemática na escola secundária, e o grupo empenhou esforços na elaboração de cursos para os professores inicialmente no Estado de São Paulo, e mais tarde, chegando a outros estados brasileiros.

O Movimento da Matemática Moderna centrava-se em dois aspectos: promover uma renovação da matemática tradicional, tendo como premissa aproximar do ensino secundário o que era ensinado nas universidades; e tornar o ensino da disciplina mais acessível, prazeroso e próximo da realidade do aprendiz, mitigando a aversão que se tinha da disciplina (BURIGO; FISCHER; SANTOS, 2008).

Os modernistas apoiaram-se em Jean Piaget (1985) que defendia que, o desenvolvimento do ser humano está subordinado a dois grupos de fatores em constante interação: a hereditariedade e a adaptação biológica, dos quais depende a evolução do sistema nervoso e dos mecanismos psíquicos elementares; e os fatores de transmissão ou de interações sociais. Dentre os quais inclui a educação. Estudou as fases do desenvolvimento descrevendo as capacidades que a criança manifesta em cada etapa, orientando até a atualidade os conteúdos a serem ensinados em cada momento da escolarização (ALMEIDA, 2010). 
Segundo Vasconcelos (1996) as publicações de Piaget dedicadas à educação têm em comum a defesa dos métodos ativos e a proposta de trabalho cooperativo como estratégia pedagógica para o desenvolvimento do pensamento experimental, da razão, da autonomia e dos sentimentos de solidariedade.

O Movimento da Matemática Moderna, foi defendido por Piaget em suas teorias quanto ao desenvolvimento humano, considerando a proposição de apenas resolver os problemas da vida cotidiana. O sujeito tinha que raciocinar de forma global, respondendo aos anseios, que a preocupação da educação deveria ser formar indivíduos capazes de produzir ou criar, e não apenas reproduzir.

É importante salientar que o movimento de modernização da Matemática buscou relacionar as estruturas da inteligência propostas por Piaget, contudo o próprio autor assevera a não direção de suas pesquisas ao processo de ensino, e ainda alerta, quanto à interpretação de suas teorias de forma a ser uma grande armadilha neste processo (PIAGET, 1985).

Neste viés, que tange o currículo de Matemática, Piaget (1985) confere que não mencionou incluir seus estudos das estruturas para o ensino, contudo, assevera que o conteúdo de Matemática que é ensinado, levaria à criança a possibilidade de chegar de forma natural a estas noções, reconhecendo que elas eram mais capazes de "fazer" do que de "entender" suas próprias ações (SOARES, 2001).

Neste estudo, vinculamos aos preceitos modernistas ao que ocorreu no estado do Paraná, onde os cadernos de planejamento são pertencentes. No Paraná, não obstante aos anseios desenvolvimentistas que o país percorria, diante da aceleração e progresso industriário, o governo de Ney Braga preponderou a importância de o estado estar vinculado à Modernização do ensino da Matemática no intuito de modificar a Matemática que estava sendo ensinada e que geraria uma nova cultura para uma sociedade em transformação (FERREIRA, 2001).

Alavancados pela crescente evolução e a objetivação dos governos anteriores, o então governador do Paraná, inseriu cinco diretrizes compreendendo o bem-estar do indivíduo, sua cultura e a participação nas questões relacionadas à economia. Passaram então a exigir, novas formas na organização do trabalho, a qualificação de mão de obra (e a adequação de currículo em que inserisse o sujeito às necessidades do mercado), demandando uma qualificação em sua formação (COSTA, 2013). 
No contexto educacional paranaense, fora inculcado esta modernização a partir das orientações curriculares previstas na década de 1970, com a inserção da Reforma do Ensino de $1^{\circ}$ grau proposta pela LDB nº5692/71 (COSTA, 2013).

\section{O Percurso Metodológico}

Ao compreender a grandeza histórica e cultural que emerge a partir desses cadernos, insurge o desejo de investigar os elementos da cultura escolar com a intenção de conhecer como era o ensino primário na década de 1980, como os conteúdos eram tratados e ensinados pela professora, a partir das fontes inventariadas dando voz aos materiais, ora esquecidos e muitas vezes descartados dos acervos pessoais e escolares, que podem fornecer elementos significativos para a reflexão sobre o passado da instituição, das pessoas que a frequentaram, das práticas que circularam e, principalmente, as relações estabelecidas entre os pares.

Ao explorar os cadernos de planejamento, fez-se necessário uma análise minuciosa concebendo-os como fontes preciosas partindo da premissa da "perspectiva do joalheiro", ou seja, analisar a partir de diferentes pontos de vista um objeto multifacetado.

Valente (2017) destaca que os cadernos escolares são um produto repleto de informações e pesquisas que estão inseridas nas investigações históricas na educação matemática, afirma ainda, que tais documentos são usados como propulsão na significação dos saberes ao longo dos tempos. Outro fato que soma a este advento é o crescente número de pesquisas que vêm acontecendo em todo o mundo em referência aos cadernos escolares, sejam eles de alunos ou professores em seus planejamentos.

No percurso deste estudo, inicialmente buscou-se fontes documentais que auxiliassem na estruturação, estabelecendo interlocuções com os cadernos de planejamento. Além dos Cadernos de Planejamento, as fontes foram constituídas com o Manual do professor, documentos oficiais e escolares, fotografias, apostilas de cursos, certificados de cursos que marcaram a história do ensino de Matemática na escola primária na década de 1980.

Além de consultar o repositório do GHEMAT Brasil que dispõe de um acervo de pesquisas e fontes históricas, bem como, publicações acerca da História Cultural, visitamos outras plataformas como a Scielo, Google Acadêmico, Biblioteca Digital da Universidade Federal de Mato Grosso/UFMT e da Universidade de Cuiabá/UNIC e Periódicos da Capes em busca de produções científicas acerca dos Cadernos Escolares ou Planejamentos, delimitando esta pesquisa no recorte de 2016 a 2020. 
A busca teve início no estado do Paraná, na cidade de Guaraniaçu, na “Escola Municipal Professor Joaquim Modesto da Rosa", onde os cadernos de planejamento foram elaborados e utilizados em sala de aula pela professora primária. Em posse dos documentos foi possível identificar e localizar outros materiais que serviram de aporte nesta pesquisa, onde com base da fundamentação teórico-metodológica pode-se interpretar os materiais e correlacioná-los ao período histórico da época, em consonância ao recorte temporal da pesquisa.

\section{Os Cadernos de Planejamento de Matemática}

Pesquisas com abordagens históricas que retratam o ensino de Matemática implicam na busca das fontes e na ausência delas, Julia (2001, p.17) recomenda ao pesquisador "fazer flecha com qualquer graveto." Outro aspecto relevante são as experiências de vida que a professora acumula ao longo da carreira. Essa troca de experiências com os alunos em sala de aula permite enriquecer o conhecimento adquirido que a cada ano se apropria, ampliando os saberes profissionais (saberes a e para ensinar) que resulta em novas oportunidades no modo de ensinar, bem como mudanças na prática cotidiana de seu ofício (VALENTE; BERTINI; MORAIS, 2017).

Utilizar os cadernos de planejamento que geralmente são materiais esquecidos nas prateleiras e com grande probabilidade de descarte, proporciona uma gama de informações que permitem trazer à contemporaneidade as práticas educacionais de outra época. Reconhecê-las como fontes de pesquisa torna-se fundamental para a (re)constituição da história do ensino da matemática, bem como, da cultura escolar. Durante a análise percebe-se a qualidade do cuidado e elaboração que disponibiliza os conteúdos de Matemática indicando vestígios importantes na construção histórica da cultura escolar da época, da pequena cidade paranaense.

Observa-se que a professora sistematizava os registros diários que contemplam todas as áreas de conhecimento e destaca de forma organizada e sequenciada as disciplinas trabalhadas em sala de aula. Nos cadernos a professora registra as atividades realizadas com a turma, identificando o dia do mês correspondente, incluindo as aulas de Educação Física, higiene bucal, que era obrigatório toda semana na estrutura curricular, tornando o caderno escolar como um de diário de campo da turma.

Ao realizarmos uma análise mais geral dos cadernos de planejamento, nosso intento foi privilegiá-los como fontes de pesquisa para que o leitor possa vislumbrar neste aparato pedagógico a possibilidade de inúmeros estudos e buscar enxergar vestígios da Matemática ensinada nos primeiros anos escolares, precisamente na quarta série primária da cidade de 
Guaraniaçu/PR na década de 1980. A análise ainda permite descrever a cultura escolar da época e os significados atribuídos aos conteúdos matemáticos trabalhados, bem como, a sequência e organização didática, o que foi vivido e ensinado no ambiente escolar.

Ao reconhecer os conteúdos trabalhados pela docente que estão presentes nos cadernos, destacou-se o método intuitivo como fator ao processo do ensinar. Acredita-se que o ideário da Escola Nova perpetuou-se no contexto histórico em que se inserem os objetos de estudo, concebendo naquele momento um novo olhar para com a educação, estabelecendo questões que centraram o sujeito como ativo no que tange ao seu aprendizado, compreendendo que o movimento centrava-se no do ensino da Matemática Moderna.

Notou-se, portanto uma preocupação em tornar a disciplina acessível aos alunos a preocupação em correlacionar a mesma aos contextos sociais. Deste modo é trabalhada a partir de atividades práticas e instrumentos concretos - por meio do método intuitivo, de modo a facilitar a assimilação do aluno a situações de seu cotidiano.

Neste contexto, o professor assume o papel de mediar a aprendizagem, a partir da proposição de atividades que desafiem a resolução, enquanto o aluno assume a postura de construtor de seu próprio conhecimento, a partir da sua relação com o meio, gerando aprendizagem e estando, constantemente, em um processo de reconstrução e ampliação de ideias (PIAGET, 1971).

As fontes apontam que a docente sistematizava cuidadosamente os conteúdos quando planejava as suas aulas. Os registros demonstram organização em relação às atividades elaboradas, com a definição de conceitos e anotações cotidianas durante todo ano letivo (Figura 2).

Ao analisarmos os primeiros registros do caderno observa-se logo no início do primeiro bimestre (24 de fevereiro de 1986), o primeiro conteúdo que aparece acompanhado com definições e contextualizado sobre o ensino do sistema de numeração, tendo como título, "Matemática Número e Numeral". 
Figura 2 - Propriedades da adição, 1985

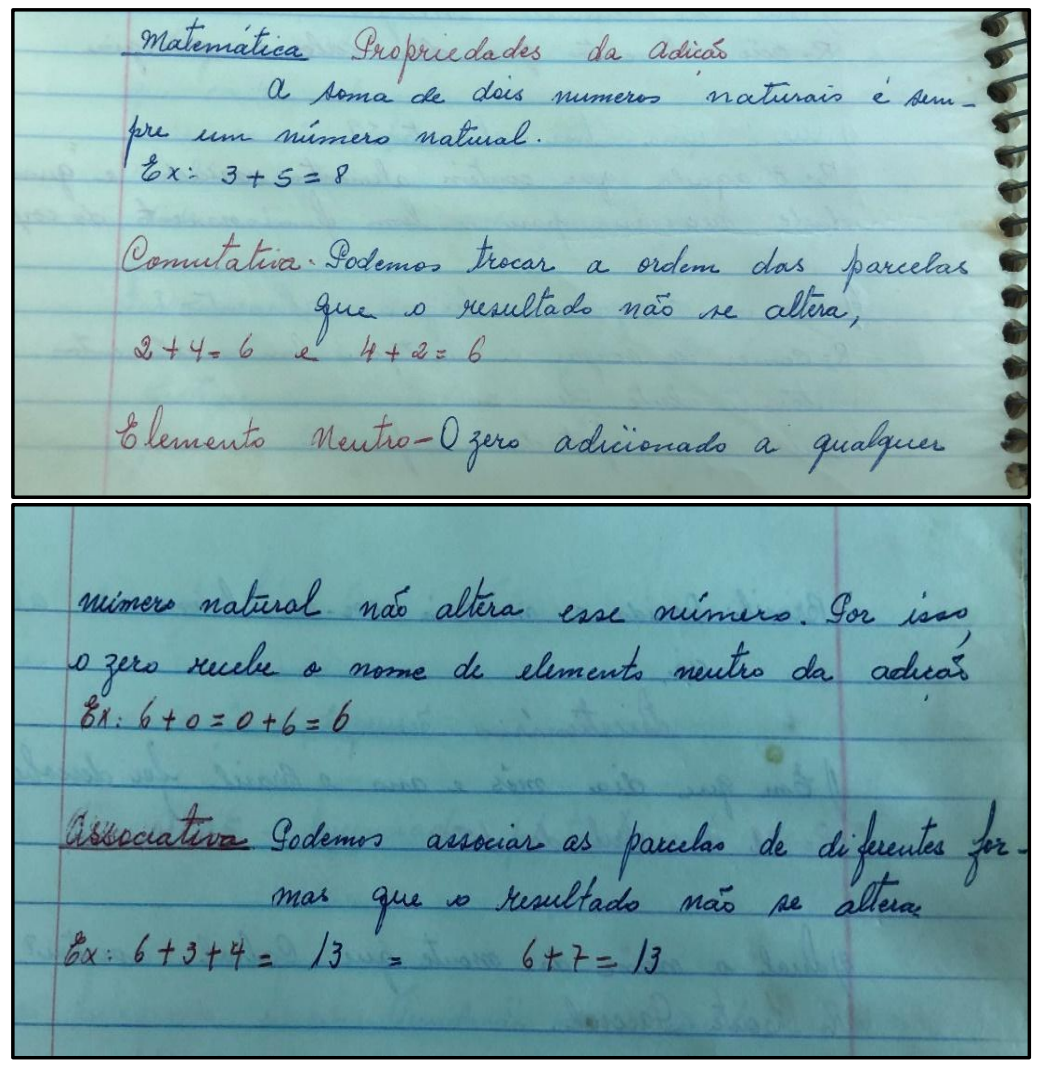

Fonte: Acervo pessoal do autor.

O enunciado do conteúdo prevê sentidos tênues ao sistema de numeração, onde ela destaca "o nosso sistema de numeração é o decimal, a contagem é feita de "10 em 10" e logo após explica que "para formar o numeral seja ele de qualquer número, utiliza os algarismos, onde registra de 0 ao 9", e por fim, cada algarismo que forma o numeral representado pela ordem e classe dos numerais", como indica a Figura 3.

Figura 3 - Sistema de numeração decimal, 1986

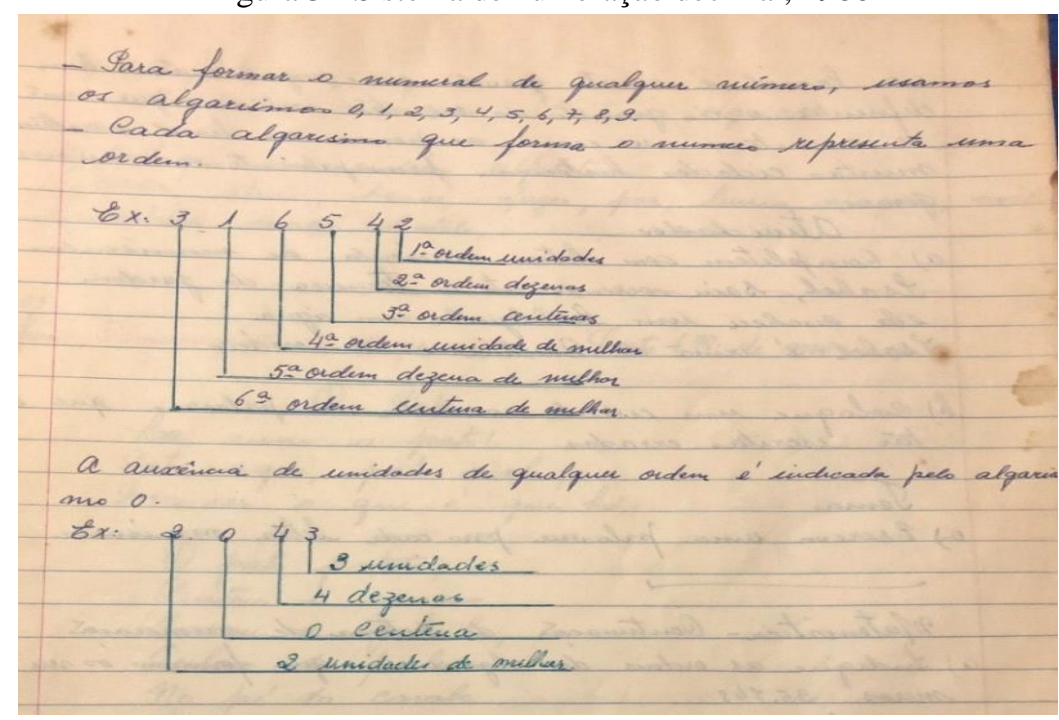

Fonte: acervo pessoal do autor. 
Outro aspecto advém da utilização de materiais que eram oferecidos tanto pela SME (Secretaria Municipal de Educação (Figura 4), quanto nos cursos de atualização profissional que eram elaborados na capital paranaense.

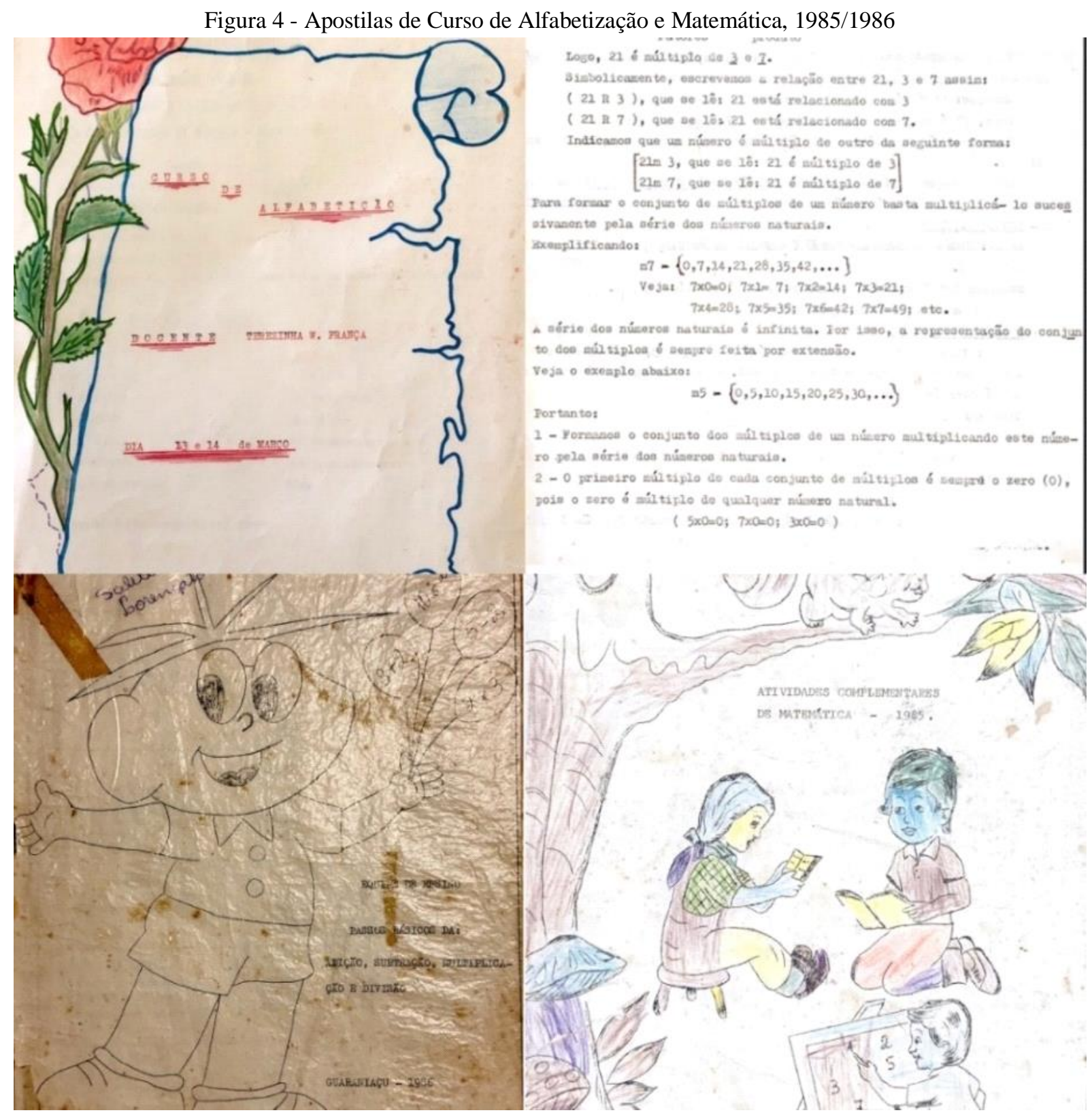

Fonte: Acervo pessoal do autor.

Ao analisarmos os conteúdos das apostilas (1986) o documento localizado no canto inferior esquerdo (C), intitulado "os passos da adição e das quatro operações" resume o material formativo sobre os passos básicos das operações de adição, subtração, multiplicação e divisão. Este material vincula-se ao ideário da modernização da Matemática, uma vez que contempla uma estrutura rígida quanto ao que deveria ser ensinado em cada etapa de ensino da disciplina. 
Tal conceito estruturalista também apresenta-se na organização sequenciada dos conteúdos dispostos nos cadernos de planejamento.

Entende-se que os estágios de desenvolvimento da inteligência propostos por Piaget, reconhecem que o aprendizado acontece de forma organizada e necessita de uma estruturação. Reitera que as estruturas matemáticas são resultantes de estruturas mentais dos adolescentes e adultos pensarem de forma lógica (ACZEL, 2009, p. 115-116). Deste modo, as demais apostilas dos cursos ofertados aos professores na época, seguem o mesmo sistema organizacional quanto aos conteúdos, apoiados nos preceitos estruturalistas.

Como já mencionado, o núcleo comum proposto para a época menciona a disciplina de Matemática junto com Ciências. Segundo o Centro de Treinamento do Magistério do Paraná (CETEPAR), a organização curricular objetivava congruentemente a Lei 5692/71 sobre conceitos e teorias:

Estimular a atitude científica, os experimentos poderão ser vivenciados pelo educando no próprio ambiente escolar, onde ele aprenderá vendo e fazendo a Matemática constituirá um dos auxiliadores vitais para as ciências. Assim, novos conteúdos programáticos segundo os objetivos a atingir, como também novas formas de apresentação será sugerida de modo que o educando como "ser pensante" participe efetivamente na solução de problemas e numa iniciação ao método científico, observe, levante hipóteses, experimente as hipóteses e chegue a conclusões (CETEPAR, 1975, p.88).

Nesse contexto, a CETEPAR deu início ao treinamento dos professores, dando ênfase ao processo de formação, visto que esses saberes eram advindos da Secretaria Estadual de Educação, órgão competente estadual. O curso distribuía o Manual do Professor "Sugestões de atividades para professores de $1^{\mathrm{a}}$ a $4^{\mathrm{a}}$ séries", como suporte para municiar o trabalho pedagógico nas escolas e, segundo a CETEPAR (1979) foram operacionalizados conteúdos e objetivos mínimos do Núcleo Comum para as primeiras séries do Ensino de $1^{\circ}$ grau.

Somente no final da década de 1970, os professores e escolas de distritos rurais do Estado do Paraná receberam o processo de implantação destes cursos, contemplando as atualizações profissionais previstas na época, com o objetivo de alcançar o maior número de professores na constituição de um saber considerado adequado ao processo de aprendizagem e se apropriassem dos métodos de ensino. No acervo familiar, destaca-se um dos cinco livros (Figura 5) que compunha a coleção que fez parte do processo de formação da professora. 
Figura 5 - Manual do Professor - Atividades, 1979

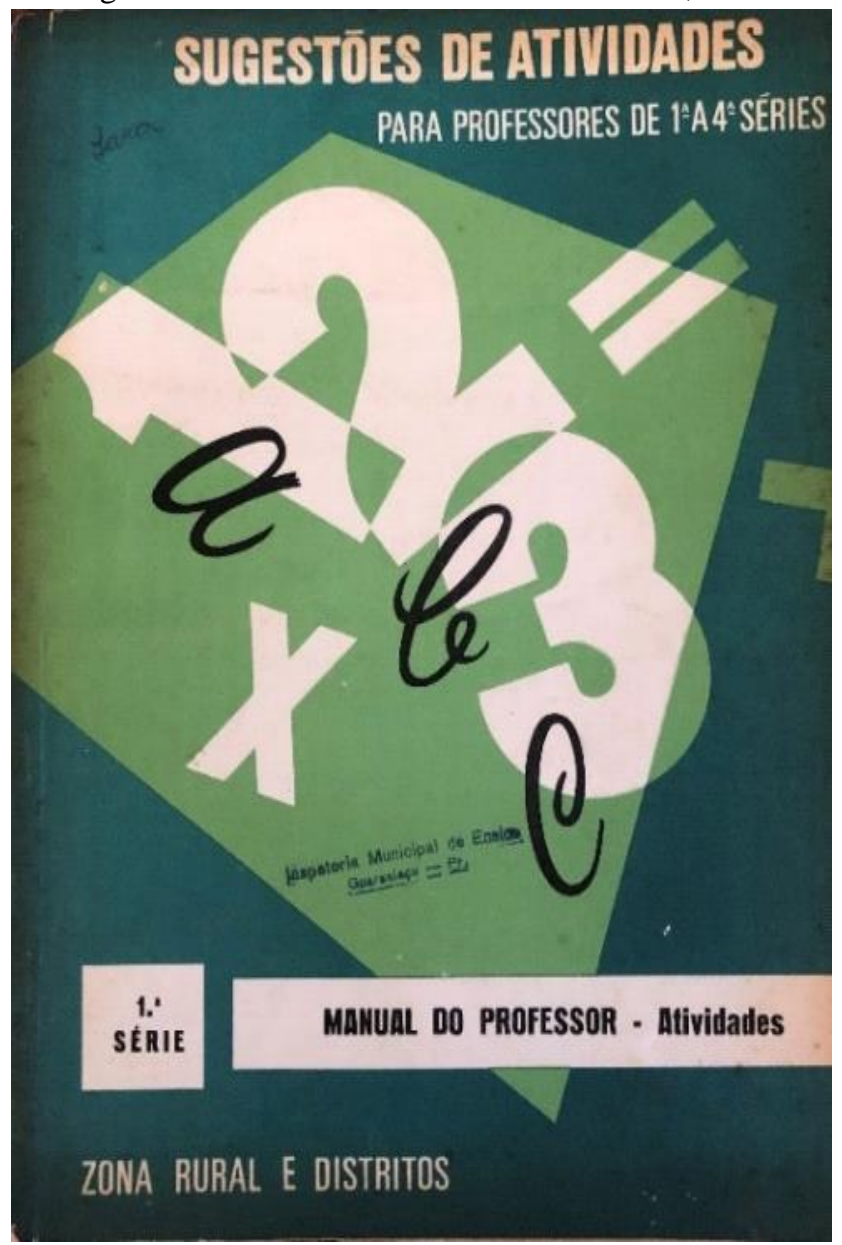

Fonte: Acervo pessoal do autor.

O material intitulado "Manual do Professor - Atividades" com sugestões de atividades para os professores de $1^{\mathrm{a}}$ a $4^{\mathrm{a}}$ séries destaca as orientações destinadas aos professores que no período eram responsáveis, sobretudo, aos afazeres administrativos da escola. Traz nas orientações um trecho afirmando que o mesmo estaria longe de ser um material acabado e sugere que a validação do mesmo seria concretizada após o seu uso.

O Manual apresenta as orientações pedagógicas, a prática profissional e os conteúdos da disciplina de Matemática no primeiro capítulo. Em sequência a disciplina de Ciências e Estudos Sociais orientando o professor tanto na variedade de exercícios, quanto nas questões metodológicas, expondo as novas maneiras de subsidiar e inovar os planejamentos durante as aulas.

Na disciplina de Matemática, mesmo não destacando o ideário da Matemática Moderna, o Manual apresenta indícios deste movimento, com destaque para a teoria dos conjuntos que se apresenta em quase todo o material, intitulado nos exercícios destinados aos alunos como Problemas ilustrados, destacado na Figura 6: 
Figura 6 - Teoria dos conjuntos - Manual do professor, Atividades, 1979

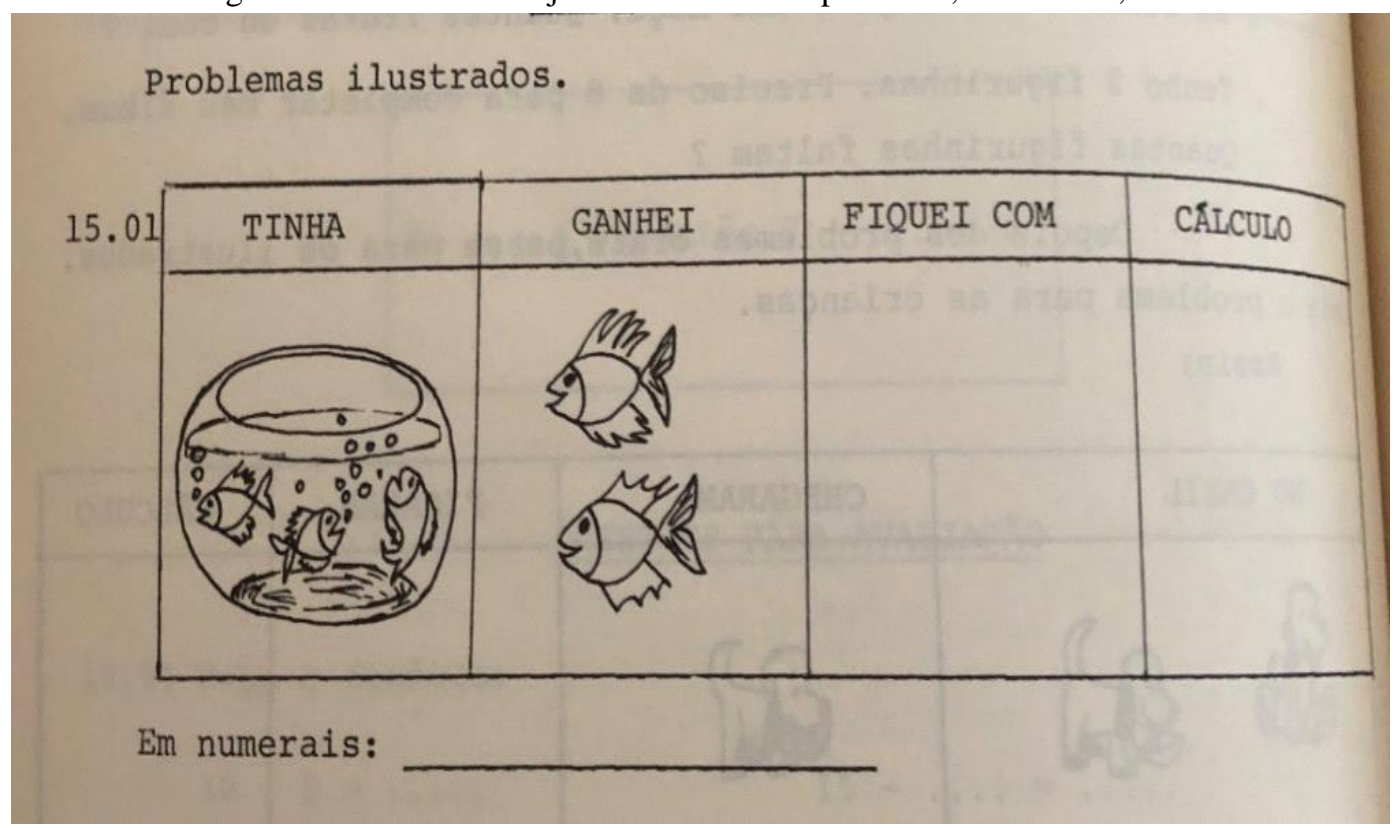

Fonte: Acervo pessoal do autor.

Reconhecendo que a Matemática por sua vez, desempenha papéis importantes no desenvolvimento do sujeito, é necessário que o professor em suas ações práticas na sala de aula, sempre que possível, proporcione atividades que possam ser aplicadas na realidade local do seu aluno, bem como, as que mais se aproximam cotidianamente do sujeito (ALVES; TATSCH, 2017). Durante a análise dos cadernos percebe-se que essa prática é facilmente identificada nas situações problemas que constam tanto no Manual do professor, (Figura 5), quanto nos registros da professora nos cadernos de planejamento de matemática (Figura 6).

A partir do momento que o professor se dispõe e traz para a sala de aula, as situações reais que fazem parte da rotina, as quais o aluno se identifica, ele consegue interagir com seu aluno e contextualizar o conteúdo trabalhado como uma das condições fundamentais para que se consolide o processo de aprendizagem (CORRÊA; MEGGIOLARO; REIS, 2019).

A noção de conjuntos é a mais antiga nos conceitos da Matemática Moderna e definida como uma coleção de objetos, de quaisquer naturezas, os quais se denominam elementos do conjunto (FERREIRA, 2001).

Medina (2012) também ressalta que a teoria de conjuntos era fundamentada em jogos e atividades, de modo a serem explorados os conceitos de inclusão, união, conjunto universo e os diagramas de Venn (o diagrama de Venn também conhecido como diagrama de Venn-Euler, é uma maneira de representar graficamente um conjunto, para isso utilizamos uma linha fechada 
que não possui auto intersecção e representamos os elementos do conjunto no interior dessa linha).

Durante a análise, foi possível perceber elementos do ensino de Matemática que são cumulativos ao saber do aluno, características presentes no movimento de modernização da matemática, como por exemplo, reconhecer o ordenamento dos números. $\mathrm{O}$ uso de sinais (Figura 7) apresentou-se como uma das menores porcentagens nos cadernos. Aparece uma única vez no caderno de 1986, contudo, mostra que a professora fez uso de várias atividades para que os alunos conseguissem se apropriar desse conteúdo.

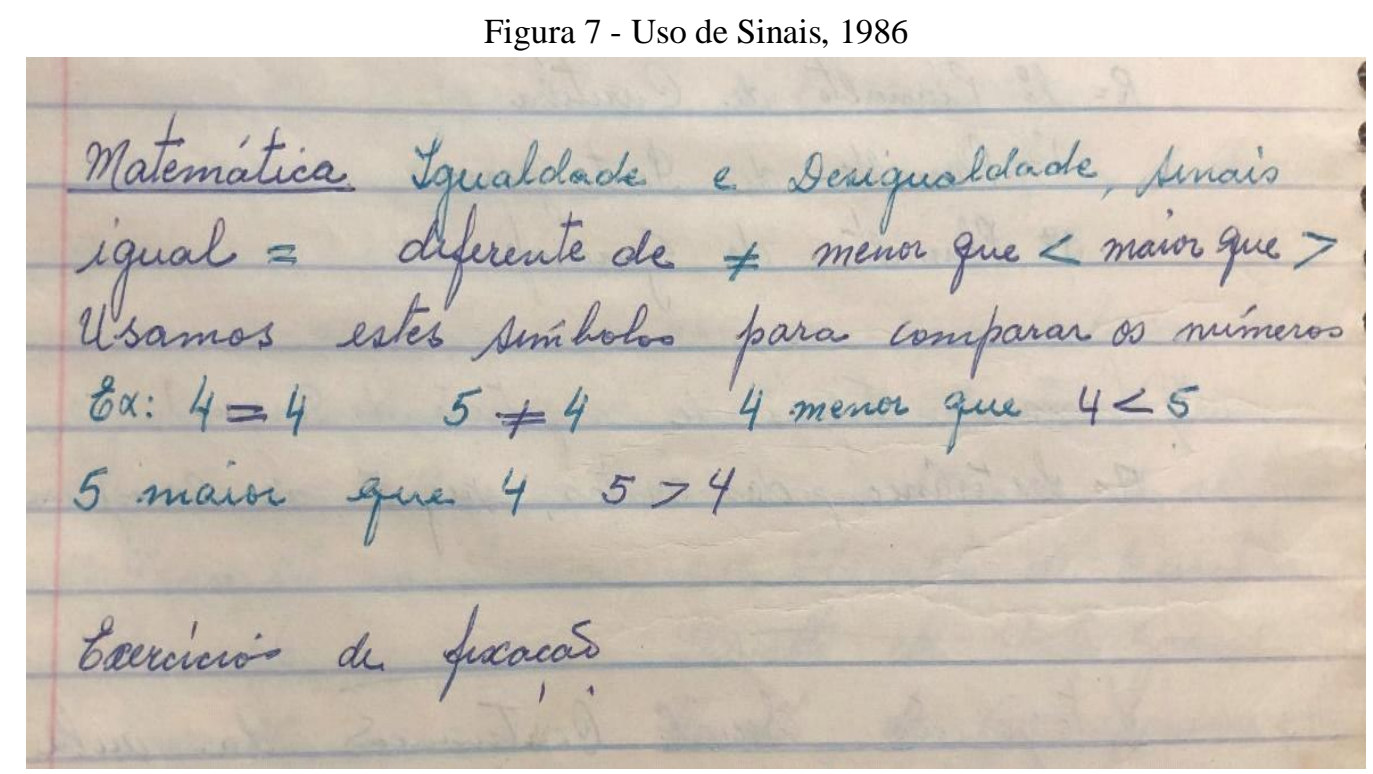

Fonte: Acervo pessoal do autor.

Quanto à matemática, entende-se que a professora trabalhava os conteúdos de forma sequenciada, demonstrando conhecimento e domínio sobre o currículo. Além disto, as exprofessoras e colegas de profissão, afirmam sobre a existência dos cursos de treinamento e aperfeiçoamento durante o exercício do magistério no período delimitado da pesquisa. Ressaltam ainda que a disciplina de Matemática não deveria ser tratada como o componente curricular mais difícil ou a disciplina que causa temor aos alunos, mas, como uma disciplina dinâmica, objetiva e lógica.

Portanto, nesta análise, por mais que não estejam explícitos nos conteúdos descritos pela professora, o MMM está presente nos registros dos planejamentos, bem como, dos materiais e recursos didáticos que possivelmente apoiou-se para dar aulas. As definições dos conteúdos, a estruturalização dos elementos matemáticos aparece nitidamente em suas folhas. 
Já nos materiais formativos, a teoria de conjuntos, foi um dos marcos que mais se destacou no período de modernização da matemática no ensino primário, mediada por simbologias a serem apreendidas nesta etapa de ensino. Soares (2001) ressalta que a unificação da disciplina de Matemática, advinha do aprendizado da teoria de conjuntos. Segundo a autora "a ênfase nos conjuntos era fundamentada no fato de ser um conceito básico da Matemática, além de uma poderosa ferramenta para a unificação da disciplina, que no século XIX era considerada como as Matemáticas” (2001, p.48).

\section{CONSIDERAÇÕES FINAIS}

A prática da história da educação matemática implica buscar respostas a questões de fundo como: Por que hoje colocamos os problemas sobre o ensino de matemática do modo como colocamos? Por que pensamos em reformas sobre esse ensino do modo como são propostas? Por que ensinamos o que ensinamos em Matemática? Por que determinados saberes matemáticos são válidos para o ensino em detrimento de outros? Essas são questões do presente, naturalizadas, não-problematizadas, que a prática da história da educação matemática tem a tarefa de desnaturalizá-las. Esse ofício de buscar revelar a historicidade dos elementos presentes no cotidiano das práticas pedagógicas do professor de matemática leva-nos a uma seara mais ampla de reflexão sobre o tempo, sobre como caracterizamos a sua cronologia e sobre como pensamos em mudanças.

A pesquisa no campo histórico da matemática propõe que o historiador produza fatos relacionados ao ensino da disciplina de outros tempos. Para tanto, faz-se necessário investigar as práticas de ensino a partir da análise da materialidade escolar, compreendida por livros didáticos, diários de classe, avaliações, documentos escolares, arquivos pessoais de discentes e docentes, bem como leis e normativas vigentes à época que, juntos, possibilitam interpretar o ensino de outras épocas (VALENTE, 2007). Assim, conhecer o passado é uma forma de compreender o presente, tendo como enfoque as práticas de ensino com o intuito de aprimorálas, a partir das experiências passadas, para as gerações futuras. Vale ressaltar que a pesquisa aqui apresentada não tem a pretensão de narrar a história da educação matemática paranaense, tendo em vista que para tanto seria necessário explorar inúmeros outros materiais e fontes que não foram contempladas nesta pesquisa. Contudo, contribui para a formação de um arcabouço que permita ampliar a construção histórica da educação matemática daquele período e naquela localidade a partir de novos trabalhos que possam se apropriar das informações aqui apresentadas. 
Nesta pesquisa, além de reconhecer como se deu o trabalho da docente na década de 80 , cabe salientar a importância de reconstituir a história do ensino de outros tempos, no intento de compreender e resgatar os aspectos culturais de um determinado povo culminando no entendimento do processo de desenvolvimento, pois, entender o passado é importante para compreender o presente.

Nas análises preliminares percebe-se que ideias modernistas poderiam estar amalgamadas nos preceitos escolanovistas, pelo formato dos registros apresentado nos cadernos. Contudo, as fontes analisadas indicam que os conteúdos trabalhados pela professora remetem ao MMM, o qual o estado do Paraná estava inserido.

Os vestígios do movimento são inerentes à maioria dos conteúdos trabalhados pela professora, como apontam os documentos oficiais da época. Vale lembrar que o Manual do Professor - Sugestão de atividades contempla os conceitos pertinentes ao movimento, como por exemplo, a teoria dos conjuntos. No entanto, nos cadernos, os vestígios mais aparentes se dão pelo estruturalismo dos conteúdos e a valorização da Matemática como ciência, com destaque para as nomenclaturas, propriedades e linguagem própria.

A pesquisa torna-se relevante pelo fato de retratar a história profissional da professora primária e analisar os conteúdos trabalhados na década de 1980 que certamente sofreram influências do período, dando voz aos documentos que têm o compromisso de desvelar todo conteúdo explícito e implícito nas páginas escritas a mão. Outro aspecto advém dos olhares a respeito dos conteúdos e registros presentes nos cadernos, não permitindo ao pesquisador nenhum tipo de julgamento, a não ser, explorá-lo didaticamente e compreender o que está posto.

Por tratar-se de um material que ainda não fora explorado por muitos pesquisadores, indica-se que não há como comparar esta temática, bem como este objetivo com outros já produzidos, visto que os cadernos são objetos pessoais do autor e permanecem em posse do mesmo, os quais posteriormente poderão ser consultados no repositório do grupo GHEMAT Brasil para que sejam realizadas outras análises no que concerne a história cultural.

Por fim, os cadernos de planejamento são relíquias de uma história recente que futuramente poderão ser revisitados e explorados por outros pesquisadores. Além da disciplina de matemática, os cadernos dispõem dos demais componentes curriculares que merecem ser analisados, possibilitando novos olhares, para além do estudo aqui produzido. Sugere-se, portanto, que novas pesquisas sejam realizadas nesta temática pela multiplicidade de conteúdo, bem como, outros olhares para além do que já foi produzido, destacando: pesquisa e busca por 
novos materiais, de outras professoras da época; relacionar os resultados desta pesquisa com as práticas pedagógicas atuais no intuito de reconhecer o percurso do ensino desta disciplina.

\section{REFERÊNCIAS}

ACZEL, Amir Dan. El artista y el Matemático - La historia de Nicolas Bourbaki, el genio matemático que nunca existió. Barcelona, Espanha: Gedisa Editorial, 2009.

ALMEIDA, Laura Isabel Marques Vasconcelos de. Ensino de Matemática nas Séries Iniciais no Estado de Mato Grosso (1920-1980): Uma análise das Transformações da Cultura Escolar. Tese Doutorado. Pontifícia Unidade Católica do Paraná. Curitiba Paraná. 2010.

ALVES, Marcos Alexandre; TATSCH, Karla Jaqueline Souza. Epistemologia, História e Ensino da Matemática: reflexões sobre formação e Aprendizagem Significativa. Revista de Ensino de Ciências e Matemática, v. 8, n. 3, p. 78-93, 28 set. 2017.

BERTINI, Luciane de Fátima; MORAIS, Rosilda dos Santos; VALENTE; Wagner Rodrigues. A Matemática a ensinar e a Matemática para ensinar: novos estudos sobre a formação de professores. São Paulo: Ed. Livraria da Física, 2017.

CETEPAR. Curso de aperfeiçoamento para professores. Sugestões de atividades para professores de $1^{\mathrm{a}}$ a $4^{\mathrm{a}}$ séries. Curitiba, 1979.

CHARTIER, Roger. História Cultural - Entre práticas e representações. Lisboa/Rio de Janeiro: Difel/Bertrand Brasil, 1990.

CHERVEL, André. História das disciplinas escolares: reflexões sobre um campo de pesquisa. Teoria e Educação, Porto Alegre, n. 2, p.177-229, 1990.

CORRÊA, Marcia Lima; MEGGIOLARO, Graziela Paz; REIS, Ana Queli Mafalda. Abordagem do conteúdo de frações a partir do Programa Nacional do Livro Didático. Revista de Ensino de Ciências e Matemática, v. 10, n. 6, p. 21-38, 10 dez. 2019.

COSTA, Reginaldo Rodrigues da. A capacitação e aperfeiçoamento dos professores que ensinavam Matemática no estado do Paraná ao tempo do Movimento da Matemática Moderna - 1961 a 1982. Tese de Doutorado. PUC - Pontifícia Universidade Católica do Paraná, 2013.

COUSIN, Alexandra de Oliveira Abdala. O Movimento da Matemática Moderna nos boletins da Sociedade Paranaense de Matemática. Revista. Diálogo Educação, Curitiba, v. 11, n. 34, p. $751-768$, set./dez. 2011

FERREIRA, Jaime Campos. Elementos de Lógica Matemática e Teoria dos conjuntos. Departamento de Matemática do Instituto Superior Técnico. 2001

FORQUIN, Jean Claude. Escola e cultura: as bases sociais e epistemológicas do conhecimento escolar. Porto Alegre, Artes Médicas, 1993.

GEERTZ, Clifford. A interpretação das culturas. Rio de Janeiro: LTC, 1989. Disponível em: 
https://search.ebscohost.com/login.aspx?direct=true \&db=edsmib\&AN=edsmib.000003808\&1 $\underline{\text { ang }=\text { pt-br\&site }=\text { eds-live } \& \text { scope }=\text { site. }}$. Acesso em: 8 jan. 2019.

JULIA, Dominique. A cultura escolar como objeto histórico. Revista Brasileira de História da Educação, v.1, n.1, p.9-44. jan./jul.2001.

MEDINA, Denise de Almeida França. Do primário ao primeiro grau: as transformações da Matemática nas orientações das Secretarias de Educação de São Paulo (1961-1979). 2012. 296f. Tese (Doutorado em Educação). Universidade de São Paulo - São Paulo, 2012.

MIGNOT, Ana Chrystina Venâncio. Cadernos à vista: escola, memória e cultura escrita. Rio de Janeiro: EDERJ, 2008.

PIAGET, Jean. A representação do mundo na criança. Rio de Janeiro, Zahar, 1985.

PINTO, Neuza Bertoni. et al. História do movimento da matemática moderna no Brasil: arquivos e fontes. Guarapuava: Editora da Sociedade Brasileira de História da Matemática, 2007.

SILVA, Claudia Mara Soares da. Concepções e práticas avaliativas no movimento da matemática moderna. Dissertação (Mestrado em Educação) Curitiba: PUCPR, 2006

SOARES, Flávia dos Santos. Movimento da Matemática Moderna no Brasil: Avanço ou Retrocesso? Dissertação de Mestrado, Pontifícia Universidade Católica do Rio de Janeiro, 2001. Disponível em:

https://app.uff.br/riuff/bitstream/1/2191/1/DMA SOARES F S 2001.pdf. Acesso em: 08/10/2020.

SOARES, Flávia dos Santos. A divulgação da matemática moderna na imprensa periódica. In: CONGRESSO IBERO-AMERICANO DE EDUCAÇÃO MATEMÁTICA, 5., 2005, Porto. Anais... Porto, Portugal: Faculdade de Ciências da Universidade do Porto, 2005.

VALENTE, Wagner Rodrigues. História da Educação Matemática: interrogações metodológicas. REVEMAT - Revista Eletrônica de Educação Matemática. V. 2.2, p. 2849, UFSC, 2007.

VALENTE, Wagner Rodrigues. (org.) Avaliação em Matemática: História e Perspectivas Atuais. Magistério: Formação e Trabalho Pedagógico. $1^{a}$ edição, São Paulo-SP: Editora Papirus, 2008.

VALENTE, Wagner Rodrigues. Os saberes para ensinar matemática e a profissionalização do educador matemático. Revista Diálogo Educacional, Curitiba, v.17, n.51, p.207-222, jan./mar. 2017.

VALENTE, Wagner Rodrigues; BERTINI, Luciane de Fátima; MORAIS, Rosilda dos Santos. Novos aportes teórico-metodológicos sobre os saberes profissionais na formação de professores que ensinam Matemática. Acta Scientiae, v.19, n.2, mar./abr., p.224-235, 2017. 
VIDAL, Diana Gonçalvez. Culturas Escolares-Estudo sobre as práticas de leitura e escrita na escola pública primária (Brasil e França, final do século XIX) Campinas, SP: Autores Associados, 2005a.

VIÑAO FRAGO, Antonio. Culturas escolares, reformas e innovaciones: entre la tradición y el cambio. (texto divulgado pelo autor e ainda não publicado), 2000. 